\title{
Heat Transfer Analysis in Heating of Steel Cylinder in a Graphite Vessel
}

\author{
Liviu Catalin BRABIE, Ken-ichiro MORI, Tao WANG and Masahiro KAWAKAMI
}

Toyohashi University of Technology, Department of Production System Engineering, Tempaku-cho, Toyohashi, $441-8589$

\begin{abstract}
As a part of investigation on the scrap-base steel making, a computer model, which could simulate the transport phenomena in heating of a steel cylinder in a graphite vessel, was developed. The model describes the numerical modeling of two-dimensional coupled turbulent flow and heat transfer in a graphite vessel. The model uses generalized transport equations, which are applicable to the gas and solid region. The governing transport equations are solved simultaneously by the ANSYS package. This model allows calculation of the temperature distribution inside the gas and solid phase, as well as convective and radiative heat transfer coefficients. Launder and Spalding's default values have been used with satisfactory results. The effect of various factors, such as steel cylinder surface conditions, gas flow rate, on the heating rate has been discussed. The values of emissivity for different surface condition have been determined. Best fitting was obtained with an emissivity's value of 0.9 for black surface and 0.2 for the polished one. The radiative heat transfer coefficients obtained were 560 (for polished surface) and $640 \mathrm{~W} / \mathrm{m}^{2} \mathrm{~K}$ (for black surface), respectively. The convective heat transfer coefficients were in the range of 13 to $33.64 \mathrm{~W} / \mathrm{m}^{2} \mathrm{~K}$, depending on the gas flow rate. The convective Nusselt number in dependence on the Reynolds and Prandtl numbers yielded to the following relation: $\mathrm{Nu}=0.75 \mathrm{Re}^{0.446} \mathrm{Pr}^{0.33}$
\end{abstract}

KEY WORDS: steel scrap; Fe-C alloy; temperature distribution; numerical simulation; convection; radiation; FEM; $\mathrm{Nu}$; Re; Pr.

\section{Introduction}

Steel scrap becomes an important iron source regarding the accumulation in the world. One problem of interest to the metallurgical industry is the heating of scrap metal. Convection and radiation are the important mechanisms of heat transfer in the heating of metals. Over the last few years this has received concentrated research attention due to the large number of applications in material processing, metallurgy, and various other thermal engineering problems $^{1,2,3,4,5,6,7)}$. In the case of a steel cylinder heated in a graphite vessel under stirring gas conditions, there are 2 main mechanisms by which heat is transferred from the crucible to the steel cylinder. These are convection and radiation. The energy emitted by the crucible is absorbed by gas and steel cylinder. Part of the heat transfer from heated crucible to the gas occurs by way of thermal convection. This is the most common way by which thermal energy is transferred from a solid surface to the gas. When the mixing motion is induced by some external agency such as pump or blower, the process is called forced convection. The present study is concerued with the development of the model for the prediction of radiative and convective heat transfer in heating of steel cylinder in a graphite vessel.

\section{Experimental procedure}

The experimental apparatus is shown in Fig. 1. The tests were performed in an induction-type furnace using a $20 \mathrm{~kg}$ capacity graphite crucible. The temperature of the crucible was measured by using a two-color pyrometer as well as by the Alumel-Chromel thermocouple fitted at the center of the graphite crucible wall. When the temperature inside the furnace reached the desired level, the specimen was immersed into the furnace for a period of time. Figure 2 shows the schematic diagram of the specimens. Solid steel cylinders with $225 \mathrm{~mm}$ length and $35 \mathrm{~mm}$ diameter were prepared from commercial black steel rod containing

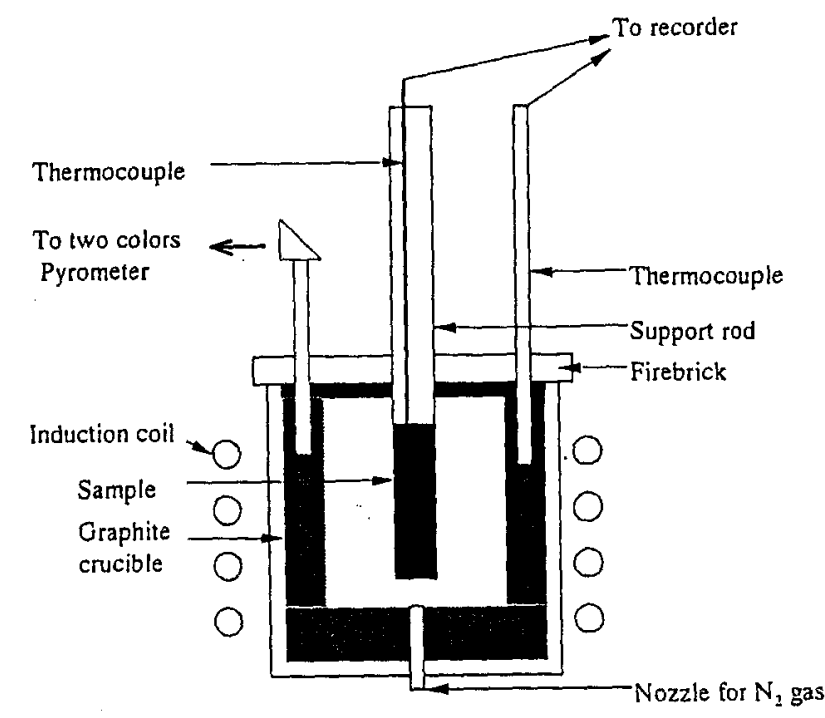

Fig. 1 Schematic diagram of the induction furnace 


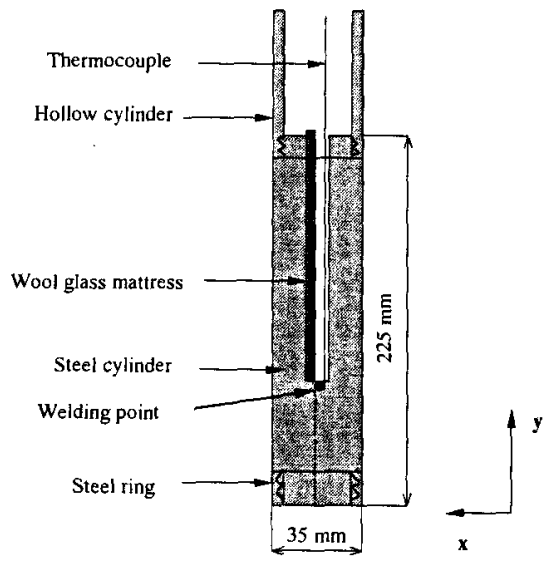

Fig. 2 Schematic diagram of the steel cylinder.

$0.26 \%$ carbon. By machining, the steel cylinders were drilled from one end to the half of the cylinder and then cut along their longitudinal axis in two hemi-cylindrical parts. The thermocouple of Alumel-Chromel was placed at the center of the hemi-cylinder. In order to obtain the quick response of the temperature change, the thermocouple was welded on the surface of hemicylinder. The inductive current flows in a circular direction, perpendicular to the y-axis in the Fig. 2. Therefore, a thin glass-wool mattress was placed in between the hemi-cylinders to prevent from picking up of inductive heating. Then the two symmetrical hemicylinders were coupled by a steel ring and by a hollow steel cylinder, which is used as a support rod. The temperature at the center of the specimen was measured as a function of time. The experiments were carried out for different surface condition of the cylinders (black surface and polished with abrasive paper ur.120). The inert gas was introduced from the bottom through a nozzle with $5 \mathrm{~mm}$ diameter. The gas flow rate was varied from 0 to $6.6 \times 10^{-3} \mathrm{~m}^{3} / \mathrm{s}$.

\section{Numerical simulation}

\subsection{Basic equations}

In many high temperature applications, radiation can completely dominate since radiant heat flow depends on the fourth power of the absolute temperature. In many practical situations, however, the convective heat transfer cannot be neglected, and is necessary to consider both modes of energy transport. The heating of a steel cylinder set in a hollow furnace is influenced by the gas flow. Therefore, basic equations consist of thermal radiation, turbulent fluid flow and convective heat transfer. The numerical simulation of the heat transfer was carried out with ANSYS, which is the general purpose-solver using the finite element method for fluid flow and heat transfer processes.

\subsection{Thermal radiation model}

Radiation is the transfer of energy via electromagnetic waves. Because the heat flow that radiation causes varies with the fourth power of the body's temperature, radiation analyses are highly nonlinear. In this model, the inert gas is considered radiatively non-participatingl). The radiation loss to the surrounding is not taking into account. The heat transfer by radiation from the graphite crucible at the temperature $T_{c}$ and the steel cylinder at the temperature $T_{\mathrm{sr}}$ can be written as:

$$
\mathrm{q}_{\mathrm{r}}=\mathrm{K}\left(\mathrm{T}_{\mathrm{c}}^{4}-\mathrm{T}_{\mathrm{sr}}^{4}\right)
$$

The above equation is not linear and cannot be solved using the linear equation solver. Therefore Eq. (1) is expanded as:

$$
q_{r}=\sigma \varepsilon_{i} F_{c r} A_{r}\left(T_{c}^{2}+T_{s r}^{2}\right)\left(T_{c}+T_{s r}\right)\left(T_{c}-T_{s r}\right)
$$

with the view factor $F_{c t}$ defined as the fraction of total radiant energy that leaves crucible surface to energy that arrives directly on the cylinder surface. The view factor can be obtained from the following equation:

$$
F_{c r}=\frac{1}{A_{c}} \int_{A_{c}} \int_{A_{r}} \frac{\cos \theta_{c} \cos \theta_{r}}{\pi x^{2}} d\left(A_{c}\right) d\left(A_{r}\right)
$$

In practice, the view factor was calculated in ANSYS.

The radiation heat transfer coefficient $h_{r}$ can be defined $\mathrm{as}^{2)}$ :

$$
\mathbf{h}_{\mathrm{r}}=\sigma \varepsilon_{\mathrm{i}}\left(\mathrm{T}_{\mathrm{c}}^{2}+\mathrm{T}_{\mathrm{sr}}^{2}\right)\left(\mathrm{T}_{\mathrm{c}}+\mathrm{T}_{\mathrm{sr}}\right)
$$

\subsection{Turbulent flow analyses}

In order to calculate the heat transfer coefficient between the steel cylinder and the fluid flow, one has to compute the tlow pattern within the vessel. In order to solve the axi-symmetric turbulent flow problem, the cylindrical coordinates were adopted and the following equations were solved ${ }^{3}$ ):

from the law of conservation of mass comes the continuity equation

$$
\frac{1}{\mathrm{r}} \frac{\partial}{\partial \mathrm{r}}\left(\rho \mathrm{r}_{\mathrm{r}}\right)+\frac{\partial}{\partial \mathrm{z}}\left(\rho \mathrm{U}_{\mathrm{z}}\right)=0
$$

The momentum equations are as follows:

-equation of motion in axial direction

$$
\begin{aligned}
& \frac{\partial}{\partial \mathrm{r}}\left(\rho \mathrm{r} \mathrm{U}_{\mathrm{r}} \mathrm{U}_{\mathrm{z}}\right)+\frac{\partial}{\partial \mathrm{z}}\left(\rho \mathrm{U}_{\mathrm{z}}^{2}\right)=-\frac{\partial \mathrm{p}}{\partial \mathrm{z}}+\frac{1}{\mathrm{r}} \frac{\partial}{\partial \mathrm{r}}\left[\mathrm{r} \mu_{\mathrm{eff}} \frac{\partial \mathrm{U}_{\mathrm{z}}}{\partial \mathrm{r}}\right]+ \\
& 2 \frac{\partial}{\partial \mathrm{z}}\left[\mu_{\mathrm{eff}} \frac{\partial \mathrm{U}_{\mathrm{z}}}{\partial \mathrm{z}}\right]+\frac{1}{\mathrm{r}} \frac{\partial}{\partial \mathrm{r}}\left[\mathrm{r} \mu_{\mathrm{eff}} \frac{\partial \mathrm{U}_{\mathrm{r}}}{\partial \mathrm{r}}\right]+\rho \mathrm{g}_{\mathrm{i}}
\end{aligned}
$$

-equation of motion in radial direction

$$
\begin{aligned}
& \frac{1}{\mathrm{r}} \frac{\partial}{\partial \mathrm{r}}\left(\rho \mathrm{r} \mathrm{U}_{\mathrm{r}}^{2}\right)+\frac{\partial}{\partial \mathrm{z}}\left(\rho \mathrm{U}_{\mathrm{r}} \mathrm{U}_{\mathrm{z}}\right)=-\frac{\partial \mathrm{p}}{\partial \mathrm{r}}+\frac{2}{\mathrm{r}} \frac{\partial}{\partial \mathrm{r}}\left[\mathrm{r} \mu_{\mathrm{eff}} \frac{\partial \mathrm{U}_{\mathrm{r}}}{\partial \mathrm{r}}\right] \\
& +\frac{\partial}{\partial \mathrm{z}}\left[\mu_{\mathrm{eff}} \frac{\partial \mathrm{U}_{\mathrm{r}}}{\partial \mathrm{z}}\right]+\frac{\partial}{\partial \mathrm{z}}\left[\mu_{\mathrm{eff}} \frac{\partial \mathrm{U}_{\mathrm{z}}}{\partial \mathrm{z}}\right]-\frac{2 \mathrm{U}_{\mathrm{r}} \mu_{\mathrm{eff}}}{\mathrm{r}^{2}}
\end{aligned}
$$

-energy equation

$$
\rho c_{\mathrm{p}} \mathrm{U}_{\mathrm{r}} \frac{\partial \mathrm{T}_{\mathrm{g}}}{\partial \mathrm{r}}+\rho \mathrm{c}_{\mathrm{p}} \mathrm{U}_{\mathrm{z}} \frac{\partial \mathrm{T}_{\mathrm{g}}}{\partial \mathrm{z}}=\frac{1}{\mathrm{r}} \frac{\partial}{\partial \mathrm{r}}\left(\mathrm{r} \lambda \frac{\partial \mathrm{T}_{\mathrm{g}}}{\partial \mathrm{r}}\right)
$$

The Spalding and Launder's two equations turbulence model $^{4 j} k$ - $\varepsilon$ have been extensively applied in materials processing to assist in analyzing a variety of flows. Therefore, the model proposed by two authors has been employed. The effective viscosity is defined as the sum of 
the laminar viscosity and the turbulent viscosity:

$$
\mu_{\text {eff }}=\mu+\mu_{t}=\mu+\frac{C_{\mu} \rho k^{2}}{\varepsilon}
$$

Through the following expression, the turbulent viscosity was evaluated:

$$
\mu_{t}=\frac{C_{\mu} \rho k^{2}}{\varepsilon}
$$

And $G$ is the viscous dissipation term

$$
\begin{aligned}
& \mathrm{G}=2 \mu_{\mathrm{t}}\left[\left(\frac{\partial \mathrm{U}_{\mathrm{r}}}{\partial \mathrm{r}}\right)^{2}+\left(\frac{\partial \mathrm{U}_{\mathrm{z}}}{\partial \mathrm{z}}\right)^{2}+\left(\frac{\mathrm{U}_{\mathrm{r}}}{\mathrm{r}}\right)^{2}\right] \\
& +\mu_{\mathrm{t}}\left(\frac{\partial \mathrm{U}_{\mathrm{r}}}{\partial \mathrm{z}}+\frac{\partial \mathrm{U}_{\mathrm{z}}}{\partial \mathrm{r}}\right)^{2}
\end{aligned}
$$

The $k-\varepsilon$ model is not valid immediately adjacent to the steel cylinder surface. A wall turbulence model is used there. Given the current value of the velocity parallel to the steel cylinder at the certain distance, an approximate iterative solution is obtained for the wall shear stress. The wall function treatment ${ }^{5)}$ is applied to compute the wall shear stress

$$
\tau_{\mathrm{w}}=\frac{\kappa \rho k^{1 / 2} \mathrm{uC}_{\mu}^{1 / 4}}{\ln \left(\mathrm{Er}_{1} \mathrm{C}_{\mu}^{1 / 4} \mathrm{k}^{1 / 2} / \nu\right)} \ldots \ldots \ldots \ldots \ldots
$$

The walls are heated and kept at a constant temperature $T_{c}$ and they are considered thermally insulated against the ambient surroundings. The inert gas entering through the nozzle has uniform temperature. The temperature drop of the crucible was not taken into account for the computations.

\subsection{Convective heat transfer model}

Following to the turbulent flow analyses as above, the convective heat flux from the gas to the steel cylinder $q_{c s}$ is given by:

$$
q_{\mathrm{cs}}=\frac{\kappa \rho k^{1 / 2} C_{\mu}^{1 / 4} C_{p}\left(T_{g}-T_{s r}\right)}{\ln \left(E_{1} C_{\mu}^{1 / 4} k^{1 / 2} v\right)+9.24 \kappa\left(\sigma_{\varepsilon} / \sigma_{t}-1\right)\left(\sigma_{t} / \sigma_{\varepsilon}\right)^{1 / 4}}
$$

$r_{1}$ is the distance from the steel cylinder.

For most turbulent flows, Launder and Spalding recommend the default values summarized in Table 1.

Table1. Constant use in basic equations

\begin{tabular}{cccccccc}
\hline $\mathrm{C}_{\mu}$ & $\mathrm{C}_{1}$ & $\mathrm{C}_{2}$ & $\sigma_{\mathrm{k}}$ & $\sigma_{\varepsilon}$ & $\sigma_{\mathrm{t}}$ & $\kappa$ & $\mathrm{E}$ \\
\hline 0.09 & 1.44 & 1.92 & 1.0 & 1.3 & 0.9 & 0.4 & 9 \\
\hline
\end{tabular}

At solid walls, the flow velocities normal to the wall are considered zero and non-slip conditions were assumed. Having determined the temperature within the gas and heat flux at steel cylinder surface obtained from Eq. (13) the convective heat transfer coefficient can be defined as

$$
h_{c}=\frac{q_{s s}}{\left(T_{g}-T_{s t}\right)}
$$

3.5 Basic equation for heat conduction inside the steel rod
The first law of thermodynamics states that thermal energy is conserved. Specializing this to a differential control volume:

$$
\rho c\left(\frac{\partial T}{\partial t}+\{v\}^{T}\{L\} T\right)+\{L\}^{T}\{q\}=\cdots
$$

Fourier's law is used to relate the heat flux vector to the thermal gradients:

$$
\{q\}=-[D]\{L\} T
$$

Combining Eq. (15) and Eq. (16) the more familiar form is as follows:

$$
\begin{aligned}
& \rho c\left(\frac{\partial T}{\partial t}+\frac{v_{r} T}{r}+\frac{\partial\left(v_{r} T\right)}{\partial r}+\frac{\partial\left(v_{z} T\right)}{\partial z}-T\left(\frac{v_{r}}{r}+\frac{\partial v_{r}}{\partial r}+\frac{\partial v_{z}}{\partial z}\right)\right) \\
& =\stackrel{q}{ }+k\left(\frac{1}{r} \frac{\partial T}{\partial r}+\frac{\partial^{2} T}{\partial r^{2}}+\frac{\partial^{2} T}{\partial z^{2}}\right)
\end{aligned}
$$

\subsection{Boundary conditions and material properties}

At the steel cylinder surface the rate of conduction of heat inside the steel cylinder equals the rate at which heat is transferred by convection from gas and by radiation from graphite vessel. Over the surface of steel cylinder, the heat fluxes defined by Eq. (2) for radiative heat flux and Eq. (13) for convective heat flux were assumed. The temperature distribution inside the steel cylinder may be determined by solving Eq. (17) subject to:

$$
\mathrm{k}\left(\frac{1}{\mathrm{r}} \frac{\partial \mathrm{T}}{\partial \mathrm{r}}+\frac{\partial^{2} \mathrm{~T}}{\partial \mathrm{r}^{2}}+\frac{\partial^{2} \mathrm{~T}}{\partial \mathrm{z}^{2}}\right)=\mathrm{q}_{\mathrm{r}}+\mathrm{q}_{\mathrm{cs}} \ldots \ldots \ldots
$$

At the interface of graphite crucible-inert gas, the following equation was assumed:

$$
\lambda\left(\frac{\partial \mathrm{T}_{\mathrm{g}}}{\partial \mathrm{r}_{\mathrm{i}}}\right)=\mathrm{q}_{\mathrm{cg}}
$$

On the surface of the graphite crucible the temperature was kept constant. An emissivity of 0.6 was assumed for the graphite crucible. The value was chosen from the literature. For the inert gas, the room temperature was assumed as initial temperature. Thermo physical properties of the inert gas are considered as variable with temperature because large temperature variation in the flow is expected. The material properties, necessary to solve the heat-transfer problem have been expressed as a function of temperature ${ }^{6}$. An emissivity in the range of 0.65 to 1 was assumed for steel cylinders with black surface, while for polished one, the values of 0.1 to 0.4 were used. The above gas flow and radiation equations were solved simultaneously.

\section{Results and discussion}

For the results presented, the inlet gas temperature was $300 \mathrm{~K}$. During the experiments it was observed that increasing the gas flow rate from 0 to $6.6 \times 10^{-3} \mathrm{~m}^{3} / \mathrm{s}$ made no significant changes in the temperature distribution inside the steel cylinder. Figure 3 shows the measured and computed results of the temperature change at the center of steel cylinder in case of radiation and free convection. The computed results are for different emissivity's values of 0.1 , $0.2,0.8$ and 0.9 . The best fitting obtained was with the 


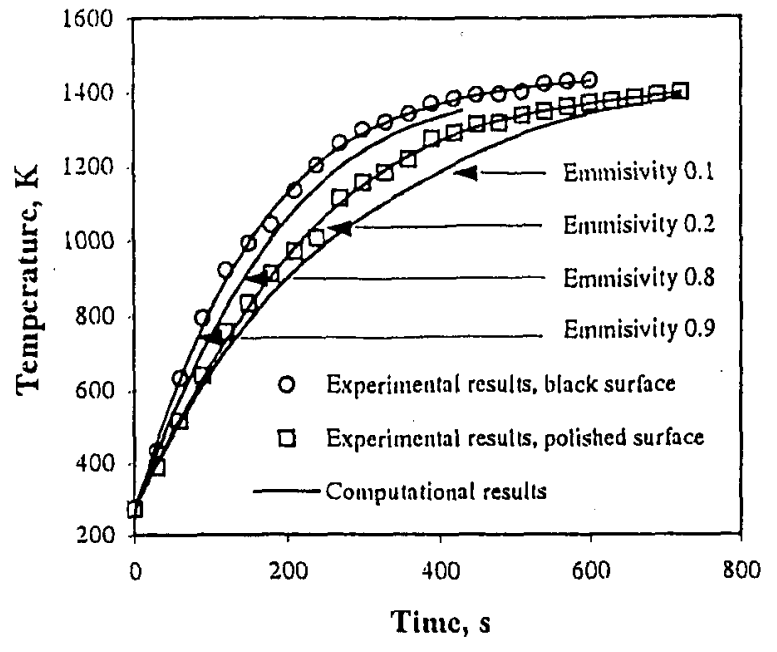

Fig. 3 Temperature versus time at the center of steel cylinder

value of 0.9 for the black surface and 0.2 for the polished one. The agreement of computed results with experimental data was also obtained in the case of radiation and forced convection for the values of emissivity given above. Figure 3 shows that the present mathematical model with parameters given in Table 1 is proved to be applicable to the present heat transfer analyses. For a black surface, the temperature is raised faster than for a polished surface. The heating rate is rather high during the early steps of the process, and decrease quite rapidly toward the final stages. The surface condition can play an important role in the heating process. A maximum of 640 (for black surface) and $560 \mathrm{~W} / \mathrm{m}^{2} \mathrm{~K}$ (for polished surface) heat transfer coefficients were obtained. The radiative heat fluxes gradually decrease as a consequence of the reduction in the temperature difference between the graphite crucible and steel cylinder. The convective heat transfer coefficients were in the range of 13 to $33.64 \mathrm{~W} / \mathrm{m}^{2} \mathrm{~K}$. Table 2 shows the convective heat transfer coefficients as functions of temperature and gas flow rate. The heat transfer coefficients gradually increase with increasing the gas flow rate. At high temperatures the gas velocity is high and thus, the convective heat transfer is accelerated.

Table 2. Values of the convective heat transfer coefficients.

\begin{tabular}{ccccc}
\hline $\begin{array}{c}\text { Temperature, } \\
\mathrm{K}\end{array}$ & 1200 & 1425 & 1450 & $\begin{array}{c}\text { Gas flow } \\
\text { rate, } \\
10^{-3} \mathrm{~m}^{3} / \mathrm{s}\end{array}$ \\
\hline Coefficient of & 13.74 & 18.89 & 21.31 & 0 \\
convective & 27.69 & 20.89 & 26.28 & 2 \\
heat transfer, & 34.32 & 28.72 & 33.64 & 4 \\
$\mathrm{Wm}^{-2} \mathrm{~K}^{-1}$ & & 32.23 & & 6.66 \\
\hline
\end{tabular}

Figure 4 shows the radiative versus convective heat transfer coefficients for different surface conditions. The convective heat transfer has a small influence in heating the steel cylinder. The radiation heat process is completely dominant.

\subsection{Heat transfer coefficient}

In order to quantify the convective heat transfer process,

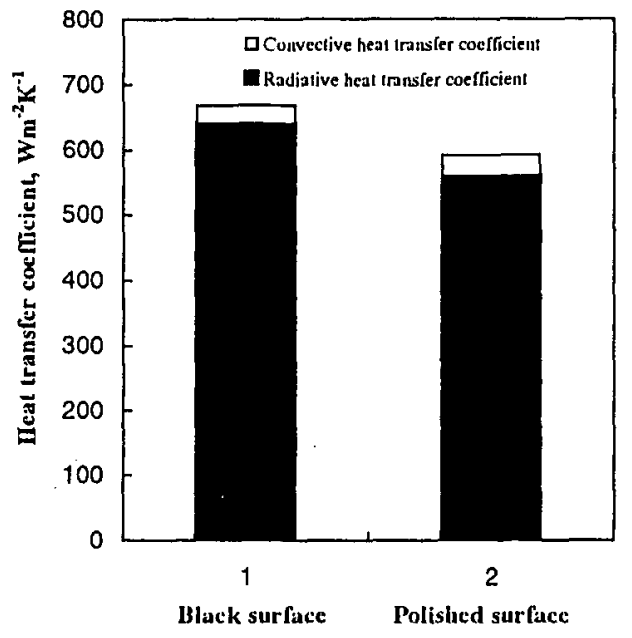

Fig. 4 Radiative versus convective heat transfer coefficients

a convective heat transfer coefficient is defined which relates the surface heat flux to a temperature difference:

$$
q=h_{\text {local }}\left(T_{s}-T_{g}\right)
$$

where $q$ is the surface heat flux, $h_{\text {local }}$ is the local convective heat transfer coefficient, $T_{s}$ is the steel cylinder surface temperature, and $T_{g}$ is the gas temperature. The average convective heat transfer coefficient is defined as:

$$
\mathrm{h}_{\text {avg }}=\frac{1}{\mathrm{~L}} \int_{0}^{\mathrm{L}} \mathrm{h}_{\text {local }} \mathrm{dL}
$$

where $\mathrm{L}$ is the surface length of steel cylinder. Several runs were performed with combination of ten different Reynolds numbers. The Reynolds numbers were in the range of $0.24 \times 10^{2}$ to $0.72 \times 10^{3}$.

The analysis of convective heat transfer coefficients involved fitting of the experimental data to the dimensionless correlation, so that the heat transport can be predicted as function of geometrical condition. The average convective heat transfer coefficient is usually presented in non-dimensional form as a Nusselt number, which involves fluid conductivity $k_{1}$ and a characteristic dimension $X$ (in case of cylinder $X=D$, where $D$ is the diameter), and is defined by the following relation:

$$
\mathrm{Nu}_{\text {avg }}=\frac{\mathrm{h}_{\text {avg }} \times \mathrm{D}}{\mathrm{k}_{1}}
$$

The most important factors affecting the formation of the flow pattern inside the furnace are the momentum transport coefficients and the intensity of the convective momentum transport. In forced flow, the most important dimensionless group to consider is the Reynolds number, which relates the intensity of the momentum transfer by convection to that of molecular mechanisms (viscosity):

$$
\operatorname{Re}=\frac{V \rho D}{\mu}
$$

The value of the Reynolds number strongly depends on the value of the characteristic velocity $V$ and the characteristic length of the steel cylinder. The computer program ANSYS gives the characteristic velocity $V$ profile along the steel cylinder. Because of the complicated and 


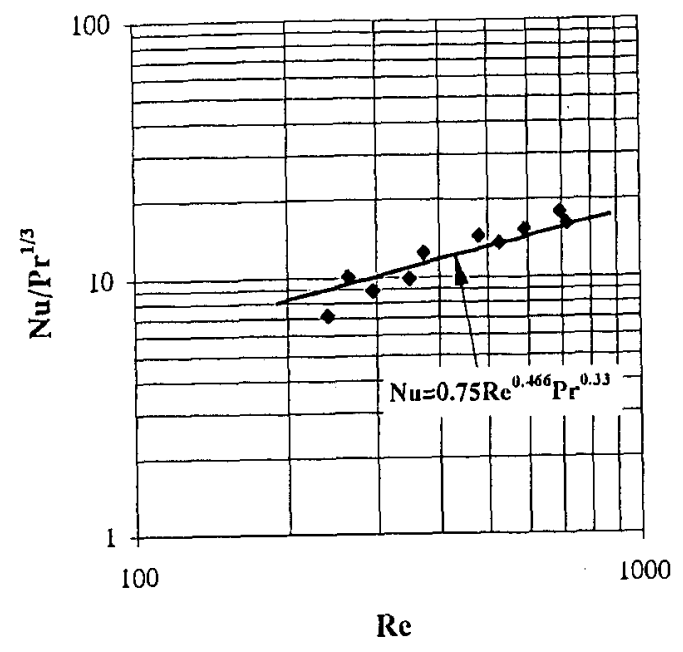

Fig. 5 Correlation of Nusselt numbers and the product of the Reynolds and Prandtl numbers

qualitatively different flow patterns the average velocity was considered. For a forced convective flow of gases around a submerged cylinder the heat transfer coefficient can be correlated in the form ${ }^{7}$ :

$$
\mathrm{Nu}=\mathrm{CRe}^{\mathrm{n}} \operatorname{Pr}^{0.33}
$$

The convective Nusselt number $\mathrm{Nu}_{c}$ can be derived by using experimental data obtained under following condition: heated graphite wall temperature $1200-1450 \mathrm{~K}$, gas flow rate from 0 to $6.6 \times 10^{-3} \mathrm{~m}^{3} / \mathrm{s}$. Figure 5 shows the convective Nusselt number in dependence on the Rayleigh number, which is direct determined from the experimental data. It can be seen that the data points can be well correlated by the following equation:

$$
\mathrm{Nu}=0.75 \operatorname{Re}^{0.466} \operatorname{Pr}^{0.33}
$$

\section{Concluding remarks}

The present paper is concerned with the development of the model for the prediction of radiative and convective heat transfer in beating of steel cylinder in a graphite vessel. The model uses generalized transport equations, which are applicable to the gas and solid region. The computed results were in satisfactory agreement with experimental data. For the turbulent flow, the Launder and Spalding's default values have been used with satisfactory results. Temperature distribution inside the steel cylinder was obtained. The computed results are for different emissivity's values of $0.1,0.2,0.8$ and 0.9 . Best fitting was obtained with a value of 0.9 for black surface and 0.2 for the polished one. The radiative heat transfer coefficients obtained were 640 for black surface and $560 \mathrm{~W} / \mathrm{m}^{2} \mathrm{~K}$ for the polished one. Surface condition can play an important role in the heating process. The convective heat transfer coefficients obtained were in the range of 13 to 33.64 $\mathrm{W} / \mathrm{m}^{2} \mathrm{~K}$, in direct dependence with gas flow rate. The radiative heat transfer is completely dominant. The convective heat transfer coefficient expressed in dimensionless correlation yielded to the following equation:

$$
\mathrm{Nu}=0.75 \operatorname{Re}^{0.446} \operatorname{Pr}^{0.33}
$$

\section{Nomenclature}

$q_{r}$ : beat transfer rate from the crucible

$\mathrm{q}_{\mathrm{cs}}, \mathrm{q}_{\mathrm{cg}}$ : heat transfer rate from the gas to the steel cylinder and crucible to inert gas, respectively

$\sigma:$ Stefan Boltzman constant

$\varepsilon_{1}$ : effective emissivity

$\mathrm{F}_{\mathrm{cr}}$ : view factor from crucible to steel cylinder surface

$\mathrm{T}_{\mathrm{c}}, \mathrm{T}_{\mathrm{sr}}, \mathrm{T}_{\mathrm{g}}$ : absolute temperature of crucible, steel cylinder and inert gas, respectively

$A_{c}, A_{r}$ : area of crucible and steel cylinder surface, respectively

$\mathbf{x}$ : distance between crucible and steel cylinder surface

$\theta_{c}$ : angle between crucible surface and radius line to steel cylinder surface

$\theta_{\mathrm{r}}$ : angle between steel cylinder surface and radius line to crucible surface

$\rho:$ density

c : specific heat

$\lambda$ : molecular thermal conductivity

$\mathrm{T}:$ temperature

$t$ : time

$\{L\}=\left\{\begin{array}{c}\frac{\partial}{\partial x} \\ \frac{\partial}{\partial y} \\ \frac{\partial}{\partial z}\end{array}\right\}$ : vector operator

$\{U\}=\left\{\begin{array}{l}U_{x} \\ U_{y} \\ U_{z}\end{array}\right\}:$ velocity vector for mass transport of heat

$\{q\}$ : heat flux vector

$\bar{q}$ : heat generation rate per unit volume

$[D]=\left[\begin{array}{ccc}K_{\mathrm{xx}} & 0 & 0 \\ 0 & \mathrm{~K}_{\mathrm{yy}} & 0 \\ 0 & 0 & \mathrm{~K}_{\mathrm{zz}}\end{array}\right]:$ conductivity matrix

\section{References}

1) D.R.Poirier, G.H.Geiger: Transport phenomena in materials science, 1994, 398

2) D.R.Poirier, G.H.Geiger: Transport phenomena in materials science, 1994, 410

3) D.R.Poirier, G.H.Geiger: Transport phenomena in materials science, 1994, 59

4) B.E Launder, D.B.Spalding: Computer methods in applied mechanics and engineering, 1974, 269

5) X.Cheng, U. Muller: Int. J. Heat and Mass Transfer, Vol.41(1998), 1681

6) D. R.Gaskell: An introduction to transport phenomena in materials engineering, Macmillian Publications, 1992, 614

7) R.I.L. Guthrie: Engineering in Process Metalurgy, Oxford Science Publications, 1993, 296 